\title{
The Effectiveness of Using Inner Speech and Communicative Speech in Reading Literacy Development: A Synthesis of Research
}

\author{
Yuan-Hsuan Lee
}

\begin{abstract}
This paper provides a theoretical understanding of inner speech and communicative speech and their impact on the process of reading literacy. The aim of this paper is to probe into questions, such as what the characteristics of inner speech are, what the relationship between inner speech and subvocalization is, what inner speech can do to help reading, and what technology can do to help practice of inner speech and literacy development. Review of literature has suggested that (1) inner speech are abbreviated form of easily stored meaning units; (2) inner speech as a form of subvocal rehearsal can retrieve information in the working memory and help solve reading problems; (3) inner speech is a mechanism that put chunks of text into compact meaning units and that elicits meanings when reading cognition becomes problematic; (4) technology can help literacy development but more emphasis should be on providing nourishing help, specifically, providing well-trained teachers and a rigorous curriculum that integrates the use of technology.
\end{abstract}

Index Terms-Inner speech, subvocalization, reading, memory.

\section{INTRODUCTION}

Inner speech put our thoughts into words and the thoughts are embedded in this inner speech all the time [1]. In a reader's inner speech, though actual articulation is not necessarily required in reading, the meaning of the words should come into the reader's consciousness. Daneman and Newson [2] commented on inner speech and its relationship to subvocalization or speech codes. They stated "many people experience inner speech that has the appropriate stress, pauses, and intonation patterns for the text being read" and that the kind of process that translate print into to sound is referred to as speech coding or subvocalization [2]. The role of subvocalization is said to recode printed words into speech so as to access their meaning held in memory [3]. Another view is that speech codes are produced after access to the words meanings and help the reader retain information in working memory for higher semantic integration [4]. Inner speech is commonly found in human reading; however, it is a rarely investigated topic because of the difficulty in observing it.This paper provided theoretical framework for inner speech, presented the characteristics of inner speech, clarified the relationship between inner speech and subvocal

Manuscript received May 5, 2014; revised July 2, 2014. This work was supported in part by the Ministry of Science and Technology, ROC under Grant NSC 102-2511-S-142 -020 -

Yuan-Hsuan Lee is with the National Taichung University of Education, Taichung, ROC (e-mail: jasvi.rms@gmail.com). rehearsal, and gave examples that suggest inner speech can improve reading ability.

\section{THEORETICAL FRAMEWORK}

\section{A. Huey's Inner Speech}

Huey held that inner speech is part of the ordinary reading [5]. Huey conducted experiments in which unrelated words were exposed four seconds each and the readers are required to state what they saw [5]. He found that "the inner pronunciation of these words and of the suggested phrases constituted much of the most prominent part of the reader's consciousness of them." (p. 118). In another series of experiments in which readers were assigned various methods to read equivalent pages from an interesting novel, nearly thirty adults who were tested found inner speech is part of their ordinary meaning in some form. "The simple fact is that the inner saying or hearing of what is read seems to be the core of ordinary reading" (p. 122) [5].

\section{B. Vyogotskian's Inner Speech}

Vygotsky maintained communication drives the speech of children and adults [6]. At beginning the purpose of speech is only for communication which develops around two years of age. Later, egocentric/private speech develops at around the age of three besides communicative speech. Finally, egocentric speech goes underground and becomes inner speech to guide self-regulation. Inner speech has three peculiarities. First, the sense of a word predominates meaning in inner speech. Meaning of a word is static while word sense is interpreted in context and differs in different situations. The second characteristic is known as agglutination that words can merge into a single word representing a complicated meaning and the meaning of individual elements. Thirdly, senses of words combine and influence one another [6].

Yaden reviewed Huey's and Vygotsky's work and concluded that "meaning in reading for children is a function of their oral language" (p. 162) [7] and that initial development of speech in children will determine what style of written language is intelligible to the child and what it isn't because early speech is the basis of internal monitoring system of inner speech which translate print.

\section{INNER SPEECH AS ABbREVIATED FORM OF EASILY STORED MEANING UNITS}

How to measure inner speech is a question that cannot be 
ignored lightly. Vygotsky [6] stated "... the area of inner speech is one of the most difficult to investigate" (p. 226). As an implicit speech reaction, inner speech is hard to be observed or assessed.

According to Huey [5] words of less importance are omitted in inner speech and will not affect the structure of the sentence. Inner speech is an abbreviated form of sound representation "but it is a tally that has its place and its time in the inner rhythmic sequence." (p. 141). Ehrich [8] commented that Vygotskian inner speech processes text during silent reading; inner speech is a mechanism that put chunks of text into compact meaning units and that elicits meanings when reading cognition becomes problematic. Vygotsky [6] noted that the nature of inner speech lies in predication. At first, a child's egocentric speech is consistent in structure with social speech. Only predicative syntax that is less complete and less coherent is left with the transformation of egocentric speech into inner speech [6]. Vygotsky's inner speech therefore is a condensed form of speech with most efficient meaning units and hence facilitates rapid reading.

\section{INNER SPEECH AND SUBVOCAL REHEARSAL}

Inner speech can appear in the form of subvocal rehearsal to retrieve information in the working memory and help solve reading problems. Inner speech has two codes; one is to retain content in short-term memory and the other is to solve problem [9]. Likewise, Ehrich [8] argued that inner speech can expands as subvocal rehearsal to solve reading problems. $\mathrm{He}$ explained Baddeley's model of working memory to demonstrate the mechanism of inner speech. Baddeley [10] proposed that working memory consists of a central executive processor and two slave systems and that inside the two slave systems verbal information is stored in phonological store and visual information in visual cache. Through the mechanism of phonological loop, verbal information is rehearsed and short-term memory or working memory is kept to prevent loss. Ehrich [8] also suggested a link between subvocal rehearsal to retain verbal information in short-term memory and Vygotskian inner speech. He contended that the transformation of egocentric speech to inner speech and children's using subvocal rehearsal to remember words both begin at around seven years of age and that "Vygotskian inner speech and subvocal rehearsal constitute the same multi-functional phenomenon" (p. 17) [8]; that is, to solve reading problems and to rehearse verbal information in short-term memory.

Similarly, Craik and Watkins [11] proposed two types of subvocal rehearsal: maintenance and elaborative. Maintenance rehearsal in subvocalization of words is for maintaining them in short-term memory while elaborative rehearsal is for more complex processing of information beyond short-term memory, both of which play important roles in dealing with written text [11]. Ehrich [8] maintained that when reading difficult text or confronted with unknown words, adults will "hear" the phonological components inside. The use of inner speech as elaborative subvocal rehearsal can help adult readers solve reading problems by resurfacing to assist in the retrieval of meaning from this unknown or rare word [8].

\section{THE USE OF INNER SPEECH AND THE IMPROVEMENT OF READING}

Liva, Fijalkow, and Fijalkow [12] conducted two experiments to see if teaching poor readers using inner speech can improve their reading and writing skills. The authors proposed that in the first stage of learning to read, children recognize words as graphical representation for symbolic meanings while in the second stage children can relate the written language to things that they say or hear, which means they realize that written language is a form of oral language. Inner speech appears at the same stage of discovering what written language is and inner speech is thought of as a mediator between the children and the text. Liva et al. [12] assigned children to experimental groups and control groups based on a pre-test and trained the children in the experimental groups to use inner speech or self-speech in reading. The result of the post-tests indicated that inner speech help children do significantly better in reading and writing.

Experiments by Beggs and Howarth [13] also showed that inner speech can help improve readers reading ability. Inner speech was found to be acquired by normally developing readers between the ages of 8 and 11, and children comprehended text better when certain prosodic features were used through inner speech [13]. Beggs and Howarth [13] conducted experiments on children age 7-11 of different reading levels. The effect of prosodic aids in reading were investigated. Some passages were enhanced prosodically through marker identifying stresses and pauses in the text. Children read the text aloud and were given comprehension questions. The study demonstrated that inner speech is not only a sound code that assist word identification but help improve readers' reading comprehension.

Moreover, Daneman and Newson [2] demonstrated that subvocal speech can enhances the storage and integration of consecutive units of text in working memory and help extract the information needed from the materials people read. Daneman and Newson [2] conducted two experiments to assess the importance of subvocalization in reading lengthy prose passages by using a concurrent speaking paradigm to suppress speech coding in working memory. In experiment one, the concurrent speaking degraded readers' ability to extract meaning from lengthy prose passage. The results in experiment two replicated those in experiment one and proved that the adverse influences of concurrent speaking was a product of competing for speech-related resources instead of cognitive resources. [2].

\section{TECHNOLOGY TO SUPPORT INNER SPEECH, COMMUNICATIVE SPPECH, AND LITERACY}

From Vygotsky's point of view, language is mainly for communication purposes and viewed language as a great mental tool that helps connect meaning to the symbols. According to Vygotsky [6], during the cognitive development of children, language is a primary way that adults convey information to children and language itself is 
indispensible for intellectual activities. Vygotsky [14] further divided language into three forms, social speech, private speech, and inner speech. Social speech is what we use to talk to others. Private speech usually starts from age three to direct self and mental activities. Private speech will turn invisible and appear in the form of inner speech that takes on the role of self-regulation.

In Voygotsky [6]"Inner speech is not the interior aspect of external speech - it is a function in itself. It still remains speech, i.e. thought connected with words. But while in external speech thought is embodied in words, in inner speech words dies as they bring forth thought. Inner speech is to a large extent thinking in pure meanings" (p. 149).

Technology can enable language learners to construct meaning in digital environment and help develop and practice the ability of inner speech for self-regulation. McLoughlin and Oliver [15] explain that the computer is a good way to support Vygotsky's [14] communicative theory of learning and authentic assessment [16]. With the assistance of technology students are more able to construct their own knowledge, as teachers as facilitators scaffold students' learning.

Norton and Gonzales [17] stated: Technology is a powerful tool to support constructive learning, which values conceptual understanding over procedural efficiency, is responsive to student's prior knowledge and experience, builds connections to the outside world, support development of higher thinking skills, and prepares for lifelong learning, and that promotes educational equity. In this sense, technology is communicative in nature. It help people to connect to the outside worlds with their prior knowledge and to construct meaning.

In order to create a better learning environment, teachers should have experience in developing students' communicative speech and inner speech to promote their literacy development. Besides, teachers should also have the technological pedagogical skills to use technology effectively in their classroom for students' learning purposes.

\section{A. Technology and Literacy}

The effect of technology on literacy development has been well documented. For example, Perez-Grandados and Huffman explore the effect of interactive books and traditional books on young children's early language and literacy skills with parent-child book sharing in low-income Latino families. The authors focus on social, collaborative (communicative) nature of learning between parents and children and offer perspectives for addressing educational inequities owing to low-income families' inaccessibility to technology.

Ricci \& Beal [18] examined the influence of interactive media on children's story memory. They authors use quantitative methods to compare students' response to four story presentation conditions. The findings showed that recollection and comprehension are lowest for students who listen to a story (audio only) but that there are no differences among other groups (audiovisual and interactive). The interactive stories appear to function similarly to television viewing in terms of children's memory. It is important for educators and researchers to play a role in the design of interactive media to be used in educational settings.

Technology intervention is especially effective for at-risk students. Macaruso, Hook, and McCabe [19] examined the efficacy of computer-based supplementary phonic program for promoting reading skills in at-risk elementary students. They found students participate in the program performed slightly better (not statistically significantly better) than those not in the program. But when focusing on the low-performing students eligible for Title I services, the authors obtained a statistically significant result that Title I students in the treatment group outperformed those in the control group and performed similarly as non-Title I students.

In another study on at-risk students, Englert, Manalo, and Zhao [20] examined the difference of at-risk first graders' composition of narratives on the computers versus paper-and-pencil style to see if they advance their writing skills in the supported paragraph, unsupported paragraph, and paper-and-pencil conditions. 10 at-risk students who had been retained or recommended for retention joined the study. The result showed that $62 \%$ of the students had better quality of introductions and text organization in the supported paragraph condition and nearly $70 \%$ of the students produced longer texts in the supported paragraph condition.

Karchmer [21] explored 13 K-12 teachers' reports of how the Internet influences literacy and literacy instruction in their classroom. He used constant-comparative data analysis that included e-mail interviews, participants' reflective journals, web pages, online articles, and lesson plans to discover how the teachers viewed the Internet's influence on reading as an extension of traditional literacy skills. The result of the study showed that elementary teachers noticed an increase in their students' motivation to write when their work was published on the Internet for a greater audience, although secondary teachers did not see such increased motivation. It is suggested that teacher technology preparation and literacy research are needed to address these issues more closely.

In addition, the features of instant feedback and self-regulated learning in computer assisted instruction help increase students' self-esteem, which can help learners to better construct their communicative speech. Diem and Katims [22] performed a seven-year longitudinal study in a four-year comprehensive high school with a high at-risk pupil population. One hundred and thirty-eight students completed the pre- and post- tests using Self-Esteem Index (SEI). Results indicated students have increased self-esteem in all aspects. Moreover, students interviewed felt more confident in their intellectual abilities and themselves, because computers allowed them to ask questions and make mistakes without any others knowing it. Other advantages of using computers for at-risk students include that teachers can spend more time with individual students and that students can work independently but still can ask the teacher questions when they need help.

\section{B. Obstacles in Using Technology to Enhance Literacy Development}

Researches have shown that the use of technology can help 
the low-achieving or at-risk students in their learning in that it increases students' motivation and self-esteem, allows them for self-paced learning, and provides customized instruction. However, teachers are not equipped with the required computer skills and professional development to incorporate computers in their instruction. Students complained that teachers are reluctant to use technology in their daily curriculum activity [22]. Many teachers are not prepared and are not able to use technology effectively within their classrooms and many of the teachers view the computer as a reward rather an integral tool to support learning [23]. For technology to be used more effectively at schools, professional development in using technology and in incorporating technology in the curriculum should come into play. Teachers have to relinquish the role of knowledge-delivering vehicle and students should collaborate with their classmates and take responsibility for their own learning. Technology is not the total solution to these problems.

Nevertheless, interventions that are designed to improve parents' computer literacy can help enhance their literacy practices at home. Duran, Duran, Perry-Romero, and Sanchez [25] reported on a year's investigation of a project design to help low-income Latino parents acquire familiarity with computers and computer related technologies as tools for learning and communication in collaboration with their children. Uses statistical tests to analyze pre- and post-assessment measures of computer awareness, computer basics, basic word processing skills, and multimedia and telecommunications familiarity and sociocultural theory to analyze qualitative data on parents' and children's interactions. Findings indicated the 18 parents made significant gains in every area of assessment and that people learning together acquire knowledge through their interactions. The project has been successful because of the blending of support for parents' learning of computer skills with sense-making literacy activities involving their children.

Zhao, Pugh, Sheldon, and Byers [24] Investigates classroom technology integration by tracking 118 K-12 teachers who were part of a technology grant program, focusing on 12 case studies. Use the constant comparison approach to analyze a variety of data that included surveys completed by all 118 participants, audiotaped interviews with 32 participants, and monthly observations and interviews of the 12 case study participants. Current efforts to prepare teachers to use technology focus to narrowly on technical skills and attitudes and that technology standards should also include the social and pedagogical contexts and implications of technology.

\section{CONCLUSION}

This paper provides a preliminary understanding of inner speech and its impact on the process of reading and probes into questions, such as what the characteristics of inner speech are, what the relationship between inner speech and subvocalization is, and what inner speech can do to help reading. Review of literature has suggested that (1) inner speech are abbreviated form of easily stored meaning units; (2) inner speech as a form of subvocal rehearsal can retrieve information in the working memory and help solve reading problems (3) inner speech is a mechanism that put chunks of text into compact meaning units and that elicits meanings when reading cognition becomes problematic (4) technology can help literacy development but more emphasis should be on providing nourishing help, specifically, providing well-trained teachers and a rigorous curriculum that integrates the use of technology.

\section{REFERENCES}

[1] R. Pintner, "Inner speech during silent reading," Psychological Review, vol. 20, pp. 129-153, 1913 .

[2] M. Daneman and M. Newson, "Assessing the importance of subvocaliztion during normal silent reading," Reading and Writing: An Interdisciplinary Journal, vol. 4, pp. 55-77, 1992

[3] M. Daneman and M. Stainton, "Phonological recoding in silent reading," Journal of Experimental Psychology: Learning, Memory, and Cognition, vol. 17, pp. 618-632, 1991.

[4] G. M. Kleiman, "Speech recoding in reading," Journal of Verbal Learning and Verbal behavior, vol. 14, pp. 323-329, 1975.

[5] E. B. Huey, The Psychology and Pedagogy of Reading, New York: Macmillan, 1908.

[6] L. S. Vygotsky, Thought and Language, Cambridge, MA: MIT Press, 1986.

[7] D. B. Yaden, "Inner speech, oral language, and reading: Huey and Vygotsky revisited," Reading Psychology: An International Quarterly, vol. 5, pp.155-166, 1984

[8] J. F. Ehrich, "Vygotskian inner speech and the reading process," Australian Journal of Educational and Development Psychology, vol. 6, pp. 12-25, 2006

[9] A. N. Leontiev, Activity, Consciousness, and Personality, Hillsdale: Prentice-Hall, 1978.

[10] A. D. Baddeley, Working Memory, Oxford: Oxford University Press, 1986.

[11] F. I. M. Craik and M. J. Watkins, "The role of rehearsal in short-term memory," Journal of Verbal Learning and Verbal Behavior, vol. 12, pp. 599-607, 1973.

[12] A. Liva, E. Fijalkow, and J. Fijalkow, "Learning to use inner speech for improving reading and writing of poor readers," European Journal of Psychology of Education, vol. 9, no. 4, pp. 321-330, 1994.

[13] W. D. Beggs and P. N. Howarth, "Inner speech as a learned skill," Journal of Experimental Child Psychology, vol. 39, pp. 396-411, 1985.

[14] L. S. Vygotsky, Mind in Society: The Development of Higher Psychological Processes, Cambridge, MA: Harvard University Press, 1978.

[15] C. McLoughlin and R. Oliver, "Maximizing the language and learning link in computer learning environments," British Journal of Educational Technology, 1998, vol. 29, no. 2, pp. 125-136.

[16] D. Healy and S. J. Klinghammer, "Constructing meaning with computers," TESOL Journal, vol. 11, no 3, pp. 3-4, 2002.

[17] P. Norton and C. Gonzales, RETA-Regional Educational Technology Assistance initiative - Phase II: Evaluating a model for statewide professional development, Journal of Research on Computing in Education, no. 31, pp. 25-48, 1998.

[18] C. Ricci and C. Beal, "The effects of interactive media on children's story memory," Journal of Educational Psychology, vol. 94, pp. 138-144, 2002

[19] P. Macaruso, P. E. Hook, and R. McCabe, "The efficacy of computer-based supplementary phonic programs for advancing reading skills in at-risk elementary students," Journal of Research in Reading, vol. 29, no. 2, pp.162-172, 2006.

[20] C. S. Englert, M. Manalo, and Y. Zhao, "I can do it better on the computer: The effects of technology-enabled scaffolding on young writer's composition," Journal of Special Education Technology, vol. 19, no. 1 , pp. 5-21, 2004

[21] R. A. Karchmer, "The journal ahead: thirteen teachers report how the internet influences literacy and literacy instruction in their K-12 classrooms," Reading Research Quarterly, vol. 36, pp. 442-466, 2001.

[22] R. A. Diem and D. S. Katims, "The introduction of computers in an at-risk learning environment: a seven-year retrospective view," Computers in the Schools, vol. 19 no. 1/2, pp. 19-32, 2002. 
[23] C. M. Reigeluth and B. J. Beatty, "Why children are left behind and what we can do about it," Educational Technology, vol. 43, no. 5, pp. 24-32, 2003.

[24] Y. Zhao, K. Pugh, S. Sheldon, and J. L. Byers, "Conditions for classroom technology innovations," Teachers College Record, vol. 104, pp. 482-515, 2002.

[25] E. Ez, "Latino immigrant parents and children learning and publishing together in an after-school setting," Journal of Education for Students Placed at Risk, vol. 6, pp. 95-113, 2001.
Yuan-Hsuan Lee was born in Taiwan. She obtained her Ph.D. in educational psychology at Texas A\&M University, College Station, USA. Her research interests are in the filed of online reading and related strategy interventions. She is currently an assistant professor at National Taichung University of Education, Taiwan. 